\title{
The laser direct deposition iron-based alloy coating with high wear resistance
}

\author{
Suiyuan Chen ${ }^{a}$, Hui Li ${ }^{b}$, Lamei Liu ${ }^{c}$, Jing Liang ${ }^{d}$, Changsheng Liu ${ }^{e}$ \\ Key Laboratory for Anisotropy and Texture of Materials (Ministry of Education), School of Material \\ Science and Engineering, Northeastern University, Shenyang 110819, China \\ achensy@smm.neu.edu.cn, ${ }^{b}$ huili@163.com, ${ }^{\mathrm{a}}$ lameiliu@163.com, ${ }^{\mathrm{d}}$ liangj@atm.neu.edu.cn, ${ }^{\mathrm{e}} \mathrm{csliu} @$ \\ mail.neu.edu.cn
}

Keywords: laser direct deposition; iron-based alloys; wear-resistant coatings.

\begin{abstract}
Using Fe55 spherical fluxed alloy power as the raw material, a Fe-based alloy coating on the surface of steel was deposited by a semiconductor laser under the optimal process parameters. The microstructure and properties of the samples were analyzed by means of OM, SEM, XRD, the micro-hardness and frictional testers. The experimental results showed that a high chromium Fe-based coating with metallurgical bonded on the substrate was deposited using the optimized process parameters with the laser power of $1900 \mathrm{~W}$; the spot size of $6 \mathrm{~mm} \times 4 \mathrm{~mm}$, the scanning speed of $5 \mathrm{~mm} / \mathrm{s}$, and the overlapping ratio of $30 \%$. The thickness of the coatings without cracks and porous was $4 \mathrm{~mm}$. The microstructure of the coating was mainly cellular and dendrite crystal. The phases of the coatings are composed of $\alpha$-(Fe, $\mathrm{Ni}$ ) solid solution, $\mathrm{Fe}-\mathrm{Cr}-\mathrm{Ni}, \mathrm{Cr}-\mathrm{Fe}-\mathrm{B}$ solid solution, and $\mathrm{Cr}_{23} \mathrm{C}_{6}$ particles. The microhardness of the coating rised to 750HV which was 4 times that of Q235 steel substrate with hardness of $175 \mathrm{HV}$, the wear resistance was 27 times that of the steel substrate.
\end{abstract}

\section{Introduction}

As one of the main components of the key parts of high speed train, the brake disc is one of the important consumable materials. Because of the extremely serious wears by the effect of sliding friction of brake disc in the work process, it need be replaced when the brake disc was worn. The brake disc of high speed train required not only high wear resistance but also good toughness to ensure the stability of the high speed train braking processing according to the failure mechanism of the brake disc during the application. This characteristic makes people realize that new brake disc can be prepared by the method of surface strengthening. This new brake disc can be prepared by using ordinary steel with strong toughness as a substrate, and then the coating with high wear-resistant is prepared on the surface of the substrate.

Laser direct deposition is one of the advanced surface preparation wear resistant coating technologies. Many important achievements have been obtained by using method of the alloy composition design, laser process parameter optimization, and carbide particle reinforced [1-8]. However, the study on in situ particles reinforced coatings with large thickness and good wear resistance by the laser direct deposition was less reported. Particularly, the coating with the thickness of $3 \sim 6 \mathrm{~mm}$ for liner is required to meet the work conditions, and the coating prepared by traditional laser cladding method often has cracks to result in the decrease of the strength and toughness.

In this paper, in order to research a new liner with high wear resistance, a Fe based coating was prepared on the surface of Q235 steel by laser using Fe55 alloy powder. The microstructure, hardness, wear resistant and the carbide particle reinforced mechanism of the samples were studied. This work would provide valuable reference for the development a new liner prepared by laser direct deposition coatings with high wear-resistant, large thickness (3-6mm) and free clacks on the surface of Q235 steel. 


\section{Experimental Materials and Methods}

\section{Materials and methods of the samples preparation.}

The Q235 steel with the dimension of $200 \times 100 \times 10 \mathrm{~mm}$ was used as the substrate. The powder was the Fe55 iron-based spherical fluxed alloy power with the particle size of $106 \mu \mathrm{m}$. The chemical composition of Fe55 powder were composed of 1.0wt.\%C, 19wt.\%Cr, 4wt.\%Si, 3wt.\%B, 13wt.\%Ni, $60 \mathrm{wt} . \% \mathrm{Fe}$. The substrate surface was ground by polishing machine and 100\# abrasive paper, then it was degreased by the acetone and alcohol before laser direct deposition. a FL-Dlight02-3000W Semiconductor laser was used with the laser beam profile of rectangular. The optimized parameters were as follows with the laser power of $1900 \mathrm{~W}$, power feeding rate of $8.4 \mathrm{~g} / \mathrm{min}$, spot size of $6 \mathrm{~mm} \times 4 \mathrm{~mm}$, scanning speed of $5 \mathrm{~mm} / \mathrm{s}$, and overlapping ratio of $30 \%$.Samples were deposited on Q235 substrates with 0.2MPa Argon as the carrier gas.

\section{Experimental analysis.}

The coatings were cut to the sizes of $10 \mathrm{~mm} \times 10 \mathrm{~mm}$ by wire-cut electrical discharge machining to obtain cross-section specimens which were vertical to the laser scanning direction. Microstructures were characterized using an OLYMPUS-GX71 optical microscope (OM) and a Shimadzu-SSX-550 scanning electron microscope (SEM). Microhardness was measured using a 401MVDTM microhardness tester at a load of $100 \mathrm{~N}$ and an indentation time of 10s. The Phase identification was performed using an X-ray diffractometer (XRD) with $\mathrm{Cu} \mathrm{K \alpha}$ radiation (wavelength $\lambda=1.5406 \AA$ ) at 40 $\mathrm{kV}$ and $40 \mathrm{~mA}$. Friction and wear tests were conducted in an abrasive wear tester using $\varnothing 8 \times 15 \mathrm{~mm}$ samples. A 60 mesh quartz sand cloth made to simulate actual working conditions was taken as the counterface material, using a test load of $2.0 \mathrm{~kg}$. The weighing method was used to obtained the wear loss amount, and the average wear loss of a single sample was the average of the values measured by 3 times. The wear resistance of test material was shown by relative wear ability $\varepsilon$, and Q235 steel as the standard sample was compared with the coating.

$$
\varepsilon=\frac{\text { wear loss of standard sample }}{\text { wear loss of test sample }}
$$

\section{Results and discussion}

\section{Microstructure of the Fe55 alloy coating coating.}

Fig. 1 showed the OM images of a single layer laser deposited coating.. The coating has a good bonding interface between the coating and the substrate which is free of cracks. It was noticed that an apparent bright band between the coating and substrate was formed as shown in Fig 1 which indicated the coating was metallurgical bonded with the substrate.

Fig. 2 showed the cross-sectional OM image of the high thickness coating prepared by the laser direct deposition. It can be seen that a dividing line was obvious between each layers. The microstructure of the coatings without cracks was homogeneous and the sample was dense. The thickness of the coating was almost $4 \mathrm{~mm}$. The SEM morphologies of laser deposited multilayer specimens were shown in Fig. 3. The formation of the bright band illustrated that the interface between coating and substrate was also metallurgical bonded which was flat and free of pores and cracks. The microstructure of deposited coating consists of cellular, mesh dendrite and columnar crystals (Fig. 3(b)-(d)). The microstructure gradually became coarsen from the first layer to the fourth layer, and some black precipitates were observed in the fourth layer. 


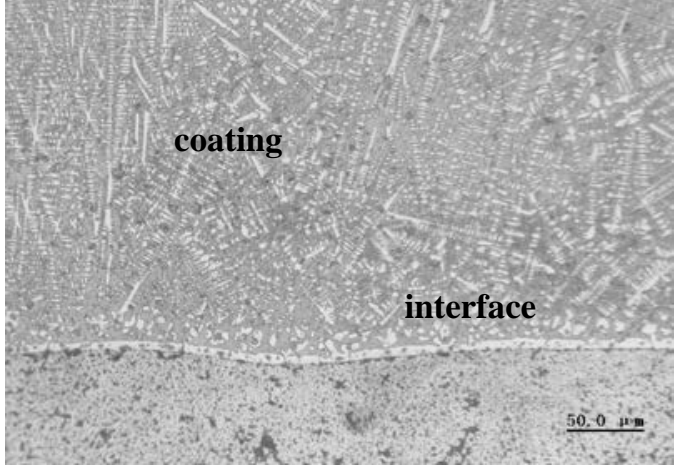

Fig. 1 The cross-section OM morphology of the laser direct deposition coating

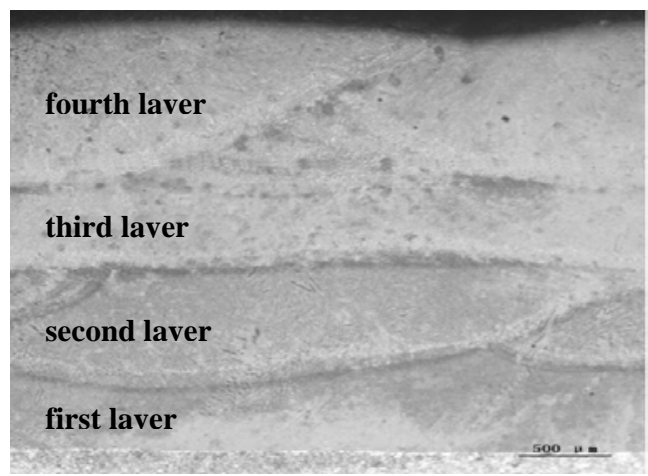

Fig. 2 The OM image of the laser deposit multilayer coating
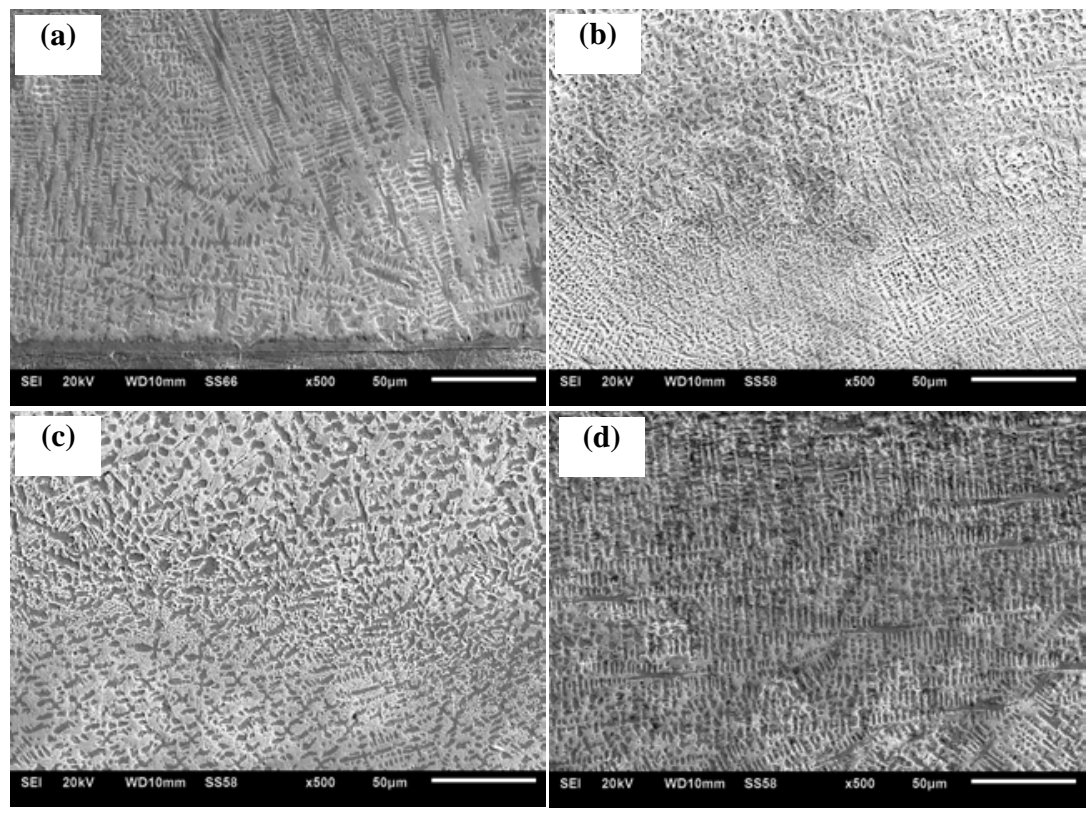

Fig. 3 The SEM images of the laser direct deposition multilayer coating(a)-interface between the coating and substrate; (b)- $1^{\text {st }}$ layer; (c)-the interface between $2^{\text {nd }}$ and $3^{\text {rd }} ;(\mathrm{d})-4^{\text {th }}$ layer

The EDS spot-scan analysis of the microstructure of the top area of the deposited four layer coating was shown in Fig. 4, and the Table 1 listed the compositions of different microstructures. Combined with the figure and table, Fe element had the highest concentration in the 093 region and more solid solution in the dendrite and cellular crystals. In addition, $\mathrm{C}$ element had a highest concentration in the black precipitates which were $\mathrm{C}_{23} \mathrm{C}_{6}$ carbide reinforced phase [9].
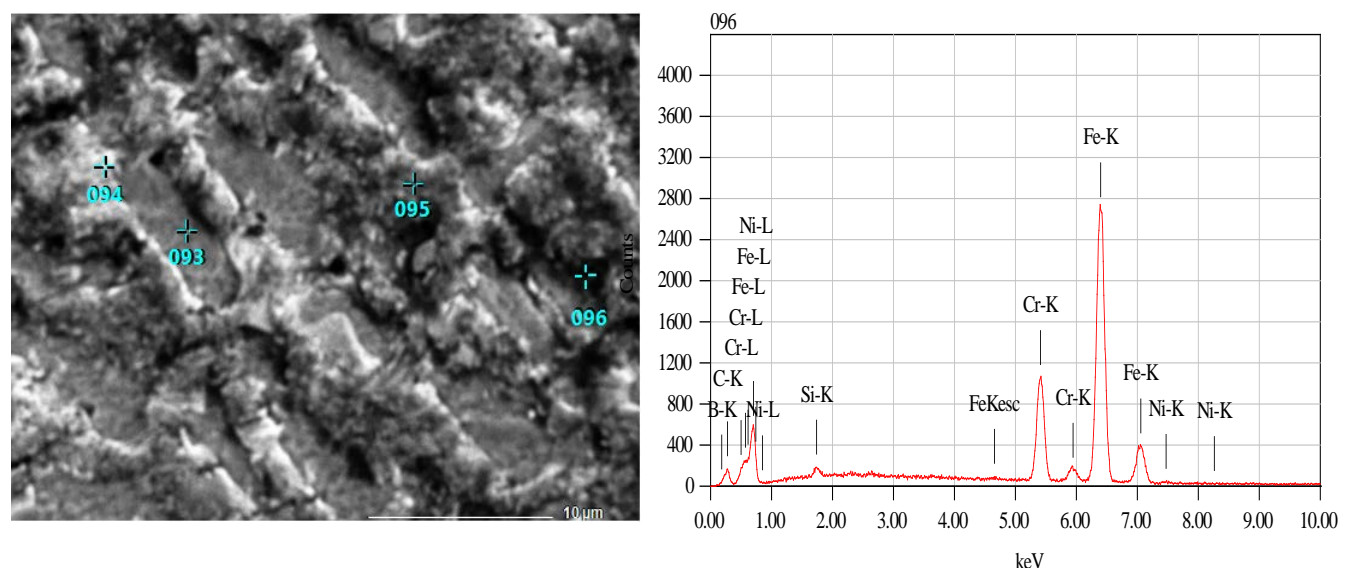

Fig. 4 The EDS analysis of the top area of the coating with high 
Table 1 The EDS element components of the different microstrcuture in the top area of the coating

\begin{tabular}{ccccccc}
\hline $\begin{array}{c}\text { Element } \\
\text { /(at. \%) }\end{array}$ & $\mathrm{C}$ & $\mathrm{Si}$ & $\mathrm{Cr}$ & $\mathrm{Fe}$ & $\mathrm{Ni}$ & $\mathrm{B}$ \\
\hline 093 & 11.63 & 1.50 & 10.61 & 75.86 & 0.39 & \\
094 & 13.44 & 1.18 & 15.63 & 69.27 & 0.48 & \\
095 & 22.26 & 0.84 & 13.26 & 51.23 & 0.38 & 12.03 \\
096 & 25.53 & 0.82 & 14.23 & 58.83 & 0.58 & \\
\hline
\end{tabular}

The XRD patterns of the laser deposited coatings are shown in Fig. 5. It was found that the coating was mainly composed of $\alpha-(\mathrm{Fe}, \mathrm{Ni}), \mathrm{Fe}-\mathrm{Cr}-\mathrm{Ni}$, Cr-Fe-B and $\mathrm{Cr}_{23} \mathrm{C}_{6}$ phases. The $\mathrm{Cr}_{23} \mathrm{C}_{6}$ particle existed in the Fe55 coating. After laser deposition, the dendritic regions were plenty of $\alpha$-(Fe, $\mathrm{Ni}$ ) supersaturated solid solution, and Si element solved in $\alpha$-Fe that strengthened the alloy.

\section{Hardness and wear resistance of the Fe55 alloy coating.}

Fig. 6 showed the cross-sectional microhardness of the laser deposited coating. It can be seen that the average microhardness increased gradually from $542 \mathrm{HV}_{0.05}$ of the first layer to $750 \mathrm{HV}_{0.05}$ of the fourth layer. The amount of $\mathrm{Fe}-\mathrm{Cr}-\mathrm{Ni}, \mathrm{Cr}-\mathrm{Fe}-\mathrm{B}$ and $\mathrm{Cr}_{23} \mathrm{C}_{6}$ reinforcing phases which increased from interface to the top area of the coating played an important role on the increase of the microhardness.

There are two reasons leading to the increase of the microhardness of the coating with high thickness. On one hand, during the laser rapid melting and solidification process, some alloy phases and in-situ particle phases were formed by the reaction among the C, B, Si, Fe, Ni and Cr elements of the power in the melt pool. As a result, the coating consisted of uniformly dispersed and small size $\mathrm{Cr}_{23} \mathrm{C}_{6}$ carbides and $\mathrm{Cr}-\mathrm{Fe}-\mathrm{B}$ reinforced phases, which leading to an obvious strengthening of the alloy matrix. On the other hand, the formation of fine microstructure under the quick heating and cooling conditions reduced the occurrence of cracks and pores so as to produce the effect of fine grain strengthening.

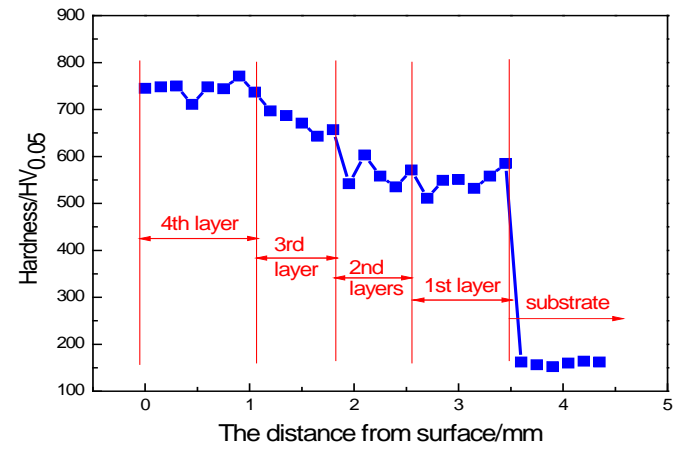

Fig. 6 The microhardness of the laser direct deposition coating with high thickness

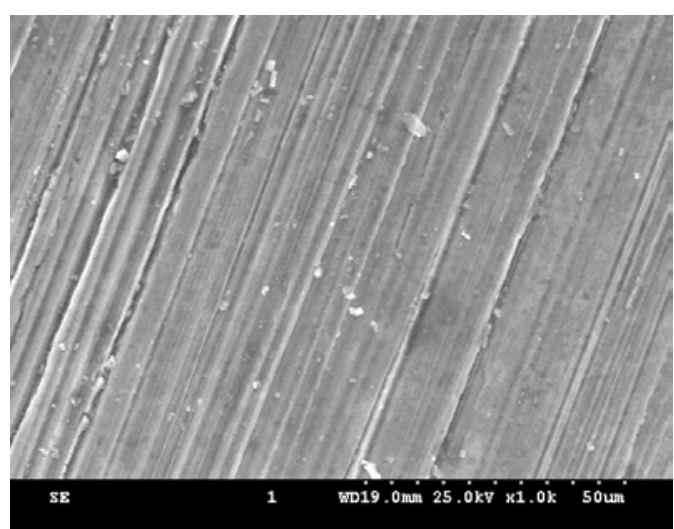

Fig. 7 SEM image of the worn surface morphology of the laser direct deposition coatings with high thickness

In order to analyze the wear properties of the multilayer coatings, the wear tests were carried out using the four layer coatings. The relative wear ability $\varepsilon=27$, the result indicated that the wear resistance of the coating was 27 times of that of the Q235 substrate. The wear surface morphology of multilayer coating was shown in Fig. 7. It can be deduced that the wear mechanism of coatings was micro-cutting type wear and the quantity of the plastic accumulation was very few in both sides of the grooves. It showed that the wear of the high-chromium Fe55 alloy coating was mainly caused by one-time cutting of the particles.

The coating with $4 \mathrm{~mm}$ thickness had high wear resistance mainly because the surface microhardness of the coating was $750 \mathrm{HV}$, and the microhardness presented a gradient distribution from the substrate to surface of the samples. Meanwhile, the toughness of the coating had been 
assured due to fine structure and no cracks and pores defect in the coating. These factors are important to form a coating with good wear resistant. In addition, the formation of $\mathrm{Fe}-\mathrm{Cr}-\mathrm{Ni}$, Cr-Fe-B and $\mathrm{Cr}_{23} \mathrm{C}_{6}$ reinforcing phases caused the microhardness to increase significantly, these compounds containing $\mathrm{Cr}$ were used as the hard barrier which play a role in preventing surface defect and in weakening the sliding effect of plastic deformation of the matrix, so as to prevent the formation and extension of micro cracks under the surface to avoid the phenomenon of stratification. Thus, the wear of the coating was controlled by different kinds of precipitated hard compound phases, the high wear resistance related to the formation of many reinforced phases containing $\mathrm{Cr}$ [10]. From the result of the experiment, we believe that the successful preparation of multilayer coating with high toughness and wear resistance using the Fe55 powder on the surface of Q235 steel under the optimized laser direct deposition parameters will provide the technical reference for studying new liner materials.

\section{Conclusions}

The optimized laser direct deposition parameters were with the laser power of $1900 \mathrm{~W}$, the spot size of $6 \mathrm{~mm} \times 4 \mathrm{~mm}$, the scanning speed of $5 \mathrm{~mm} / \mathrm{s}$, the overlapping ratio of $30 \%$, and with the power feeding rate of $8.4 \mathrm{~g} / \mathrm{min}$ using $0.2 \mathrm{Mpa}$ Argon as the carrying gas. The Fe55 alloy coating without cracks and pores was successful prepared on the Q235 steel, the thickness of the coating was $4 \mathrm{~mm}$. There were cellular and mesh dendrite crystals in the coating, the phase of coating were composed of $\alpha-(\mathrm{Fe}, \mathrm{Ni})$ solid solution, $\mathrm{Fe}-\mathrm{Cr}-\mathrm{Ni}, \mathrm{Cr}-\mathrm{Fe}-\mathrm{B}$, and $\mathrm{Cr}_{23} \mathrm{C}_{6}$ particles. The microhardness of the coating rised to $750 \mathrm{HV}$ and was 4 times that of Q235 steel substrate, and the wear resistance was 27 times that of the steel substrate. The coating prepared by this method had good wear resistance because of its characteristics such as high hardness, refined microstructure, in-situ particle reinforcement and no cracks.

\section{Acknowledgements}

This work was financially supported by National Key Research Project(2016YFB1100201), National Natural Science Foundation of Liaoning United fund (U1508213), the Fundamental Research Funds for the Central Universities (N130810002), Science and Technology Plan Project of Liaoning Province (2014221006), and Science and Technology Plan Project of Guangdong Province (2015B010122001).

\section{References}

[1] Y. Wang, Y. Zhao, J. Sun, Applied Mechanics and Materials, 696(2015)70-75.

[2] S. Chen, J. Liang, C. Liu, K. Sun, J. Mazumder, Applied Surface Science, 258(2011)1443-1450.

[3] M. Masanta, P. Ganesh, R. Kaul, A.K. Nath, A. Roy Choudhury, Materials Science and Engineering, 508(2009)134-140.

[4] Z.K. Fu, H.H. Ding, W.J. Wang, Q.Y. Liu, J. Guo, M.H. Zhu, Wear, 330-331(2015)592-599.

[5] C. Zhang and Y. Shi, Laser Technology, 35(2011) 448-452.

[6] A. Maniya, F. Hasse, Surface \& Coatings Technology, 207(2012) 32-37.

[7] C. Lou, Y. Lu, F. Luo, G. Dong, J. Yao, Applied Laser, 33(2013)14-17.

[8] D. Wang, Z. Tian, S. Wang, L. Shen, Applied Mechanics and Materials, 217-219(2012)1006-1009.

[9] S. Anshul, B. Dahotre Narendra, Metallurgical and Materials Transactions, 2005, 36(2005):797-803.

[10] A.S. Khanna, S. Kumari, S. Kanungo, A. Gasser, Metals Hard Mater, 27(2009)485-493. 